\title{
EVALUATION OF SAFETY AND EFFICACY OF PERCUTANEOUS NEPHROLITHOTOMY FOR THE TREATMENT OF RENAL STONES IN CHILDREN: EXPERIENCE OF A TERTIARY CARE MEDICAL CENTER
}

By

\section{Ahmed Abd Al-Azim Abd Al-Aziz Metwally, Yasser Ali Ahmed and Al- Sayed Mohamed Mousa}

Department of Urology, Al -Azhar Faculty of Medicine, Cairo, Egypt

Corresponding author: Ahmed Abd Al-Azim Abd Al-Aziz Metwally,

Mobile: 01281699140, E-mail: drahmeduro@yahoo.com

\begin{abstract}
Background: Renal stone disease in children is uncommon and causes a clinical management dilemma due to the size of the urinary tract in children and risk of recurrence. The majority of renal stones are due to metabolic disorders or urinary tract infections with a consequently high lifetime risk of recurrence.

Objective: To evaluate safety and efficacy of percutaneous nephrolithotomy for the treatment of pediatric renal stones.

Patients and Methods: A prospective clinical trial was carried out during the period from February 2018 to October 2019 of thirty pediatric patients $\leq 18$ years old with renal stones $>2 \mathrm{~cm}$, shock wave-resistant stones $<2 \mathrm{~cm}$, and failed chemolysis for radiolucent stones. Patients underwent percutaneous nephrolithotomy (PNL) with tract dilation up to 16 fr. A 8/9.8 Fr semirigid ureteroscope (Richard Wolf, Germany), and Ho: YAG Laser lithotripsy were used. Patients were followed up after 3 months of the operation by plain X-ray (Kidney, ureters, bladder [KUB]) (or pelvi abdominal ultrasound [US] for radiolucent stones) \& renal isotope to assess safety and efficacy of percutaneous nephrolithotomy. The data were analyzed using the appropriate statistical tests.

Results: Our study showed that PNL achieved high stone clearance rate $(86.7 \%)$ for management of renal stones in children, with accepted postoperative morbidity. The mean age was 8.48 years (range $2-18$ ). Mean diameter of the stone was $21.68 \pm 5.55$ with a range $10-30 \mathrm{~mm}$. Mean operative time was $106.93 \pm 13.89$ with a range $85-135$ minutes. Mean hemoglobin loss was $1.1 \mathrm{~g} / \mathrm{dl}$. Mean hospital stay was $3.76 \pm 0.93$ days (range: $3-6$ days). In our study, renal isotope showed that renal function did not change postoperatively.
\end{abstract}

Conclusion: PNL is a safe and effective procedure for management of renal stones in children.

Keywords: Percutaneous nephrolithotomy, renal stones in children.

\section{INTRODUCTION}

Pediatric urolithiasis is a significant health problem, and there is an increase in incidence due to the change in lifestyle, dietary habits and obesity (Muslumanoglu et al., 2011).
Surgical treatment can be used when stones are larger or more complex and unbroken by extracorporeal shock wave lithotripsy (SWL). Children have less tolerance for bleeding, which can cause an anxiety for surgeon. Therefore, minimally 
invasive techniques have become more important in the treatment of urolithiasis in pediatric age group (Tekgül et al., 2015).

This study aimed to evaluate safety and efficacy of percutaneous nephrolithotomy for the treatment of pediatric renal stones.

\section{PATIENTS AND METHODS}

Our prospective study was done on thirty pediatric patients aged less than 18 years old with renal stones.

Percutaneous nephrolithotomy was performed for all patients at Urology Department at Al-Azhar University in Cairo, Egypt during the period between February 2018 and October 2019.

An approval from Ethical Committee at Faculty of Medicine at Al-Azhar University was obtained. Written consent signed by parents of the patient was obtained.

In our study PNL was the first treatment option for patients with renal stones $>2 \mathrm{~cm}$ and shock wave-resistant stones $<2 \mathrm{~cm}$. Also PNL was performed in the case of failed chemolysis for radiolucent stones.

Pretreatment evaluation included a detailed history, physical examination, complete blood count, coagulation profile, random blood sugar, urine analysis, urine culture and sensitivity, abdominal ultrasonography (US), plain X-ray (Kidney, ureters, bladder [KUB]), no contrasted computerized tomography (NCCT) and renal scan were done for all. Prophylactic antibiotic (third generation cephalosporin) was administered at induction of anaesthesia. Patients' demographic details, procedural information (stone burden, laterality, procedural time), and postoperative parameters (PNL stone clearance rate, duration of hospitalization, hemoglobin decline, complication rates, auxiliary methods) were prospectively documented. Stone size was determined by measuring the longest axis on preoperative radiologic investigation.

\section{TECHNIQUE}

Under general anaesthesia, the patients positioned in the lithotomy position. Cystoscopy was done and ureteric catheter (4 to $6 \mathrm{Fr}$ ) placed and secured to a Foley catheter.

Patient placed in prone position with appropriate padding placed under the chest region to avoid pressure sores and to provide adequate ventilation during the procedure. We started the procedure by selecting the entry route for the percutaneous access into the collecting system.

Stone location and stone burden were the main considerations in choosing the optimal site for puncture. Puncture needle advanced into the selected calyx guided by the $\mathrm{C}$-arm in the vertical position. Once the puncture made, the inner style was removed from the puncture needle to show urine and contrast material coming out of it. A working curved guide wire $(\mathrm{J}$ tipped) was then advanced into the collecting system with its tip being passed either into an upper calyx or down across the UPJ then a second guide wire was fixed and used as a safety wire. After placement of the guide wires, the tract was dilated sequentially upto $16 \mathrm{fr}$.

Visualisation, fragmentation and extraction of the stone were done using a 
8/9.8 Fr semirigid ureteroscope (Richard Wolf, Germany).Continuous irrigation was performed using warm isotonic solution. Under direct vision, the stone was fragmented by Ho: YAG Laser (500mm fiber; energy $0.8 \mathrm{~J}$; Wavelength $2.1 \mu \mathrm{m}$; Output (max.) $30 \mathrm{~W}$; Pulse energy $200-4.000 \mathrm{~mJ}$; frequency 12 $\mathrm{Hz})$.. The big fragments $(0.3 \mathrm{~cm}-0.5 \mathrm{~cm})$ will be extracted with a $5 \mathrm{~F}$ forceps (Richard Wolf, Germany), and the fragments $<0.3 \mathrm{~cm}$ will be pushed out with a suction device or flushing through the ureteric catheter. Reinspection was done to assess the extent of clearance through direct vision and fluoroscopy. Ante grade pyelography was performed to evaluate the collecting system and assess the amount of extravasation. After finishing the procedure a nephrostomy tube was fixed.

Post-operative Evaluation: Initial stone free rate defined as stone free status or insignificant fragments less than $4 \mathrm{~mm}$ in KUB (or US for radiolucent stones) done 24-48 hours post operatively. Follow up after 3 months by KUB, pelvi abdominal $\mathrm{U} / \mathrm{S} \&$ renal isotope.

Data were collected, revised, coded and entered to the Statistical Package for the Social Science (IBM SPSS) version 20. The data were presented as numbers and percentages for qualitative value and as mean $\pm \mathrm{SD}$ and range for quantitative values.

\section{RESULTS}

Our study included 30 patients (11 male and 19 female). The average age of the patients included in our study was $(8.48 \pm 4.08)$ years \{Range from $2-18$ years $\}$. Stones were localized inside right $(n=11)$ or left $(n=19)$ kidneys. They were detected in the renal pelvis $(n=20,66.7 \%)$ and calyces $(\mathrm{n}=10,33.3 \%)$.The mean diameter of the stone was $(21.68 \pm 5.55)$ with a range $(10-30 \mathrm{~mm})$. As regard medical complaint, 17 patients presented with pain $(56.67 \%), 7$ patients presented with hematuria $(23.3 \%), 6$ patients presented with UTI (20\%) Table (1).

Table (1): Patient demographics, Stone characteristics and Medical complaint

\begin{tabular}{|c|c|c|}
\hline \multicolumn{2}{|c|}{ Variables } & Data \\
\hline \multicolumn{2}{|c|}{ Number of patients } & 30 \\
\hline \multicolumn{2}{|c|}{ Mean age \pm SD (years, range) } & $8.4 \pm 4.0(2-18)$ \\
\hline \multicolumn{2}{|c|}{ Male: female $(\%)$} & $11: 19(36.7: 63.3)$ \\
\hline \multicolumn{2}{|c|}{ Mean stone diameter $\pm \mathrm{SD}(\mathrm{mm}$, range $)$} & $21.6 \pm 5.5(10-30)$ \\
\hline \multicolumn{2}{|c|}{ Laterality R/L } & $11 / 19$ \\
\hline \multirow{2}{*}{ Location } & Pelvis & 20 \\
\hline & Calyceal & 10 \\
\hline \multirow{3}{*}{ Medical Complaint } & Hematuria $(\%)$ & $7(23.3 \%)$ \\
\hline & Pain (\%) & $17(56.7 \%)$ \\
\hline & UTI $(\%)$ & $6(20 \%)$ \\
\hline
\end{tabular}


Mean operative time was (106.9 \pm 13.89) with a range ( $85-135$ min.). Mean Hemoglobin loss was $1.1 \mathrm{~g} / \mathrm{dl}$ which was clinically insignificant. Regarding the complications; total complications were $23.3 \%$. Five patients develop postoperative fever (16.67\%) which required antibiotic and antipyretic, one patient with renal pelvic perforation (3.3\%) treated by leaving nephrostomy tube longer and one patient (3.3\%) developed persistent leakage after removal of nephrostomy tube who was treated conservatively.

Mean length of hospital stay was (3.76 $\pm 0.93)$ with a range of 3- 6 days. As regard renal function, there was no statistically significant change (P-value 0.27 ) in the split renal function of the affected renal unit done 3 months postoperatively. In our study 26 patients $(86.67 \%)$ achieved complete stone clearance while 4 patients $(13.3 \%)$ had residual stone fragments (more than $5 \mathrm{~mm}$ ) Table (2).

Table (2): Intraoperative and Postoperative parameters

\begin{tabular}{|l|c|}
\hline \multicolumn{1}{|c|}{ Variables } & Data \\
\hline Mean Operativ time \pm SD $($ minutes, range) & $109.9 \pm 13.8(85-135)$ \\
\hline Mean length of hospital stay \pm SD( days, range) & $3.7 \pm 0.93(3-6)$ \\
\hline Postoperative hemoglobin decrease (mean \pm SD) & $1.1 \pm 0.37$ \\
\hline Stone clearance rate $(\%)$ & $26 / 30(86.7 \%)$ \\
\hline Complications (\%) & $5 / 30(16.7 \%)$ \\
Fever & $1 / 30(3.3 \%)$ \\
Pelvic injury & $1 / 30(3.3 \%)$ \\
Leakage & \\
Mean change in split functin & $42.69 \pm 8.05$ \\
Preoperative (mean \pm SD) & $42.94 \pm 8.28$ \\
3 months postoperative (mean \pm SD) & 0.27 \\
P-value & 1 \\
\hline Auxiliary procedure & 3 \\
URS & \\
SWL & \\
\hline
\end{tabular}

\section{DISCUSSION}

Surgical management of urolithiasis in children has evolved dramatically in the last two decades. In the 1980s, the advent of SWL revolutionized pediatric stone management, and it is currently the procedure of choice for treating most upper tract calculi in industrialized nations. Today, SWL is one of the main modalities for treating pediatric renal stones, and selected cases can be managed effectively and safely using SWL. However, the long-term effects of shock waves on developing kidneys are not clear and many studies have shown that the success rate of SWL decreases significantly with increasing stone size and number (Kumar et al., 2014).

Percutaneous nephrolithotomy (PNL) has significantly higher stone-free rates and lower requirements for ancillary procedures compared with SWL (Unsal et al., 2010).This trend is further promoted by the introduction of mini-PNL, which is postulated to be less invasive compared with standard PNL because of the miniaturized instruments. However, PNL may present problems in children, despite 
modifications such as the "mini-perc," because of the small size and mobility of the pediatric kidney, friable renal parenchyma, and the small size of the collecting system. Today, PNL is typically reserved for larger stone burdens and failed SWL treatments because of its more invasive nature (Bilen et al., 2010).

In our study; Stone free rate (SFR) was $86.7 \%(26 / 30)$ that was comparbable to Other studies done by Karatag et al. (2015), D'Souza et al. (2016) and Elsheemy et al. (2016) reported SFRs $93.6 \%, 90 \%$ and $94.4 \%$ respectively. Kumar et al. (2015) reported that auxiliary procedure rates were $5.6 \%$. Elsheemy et al. (2016) reported that auxiliary procedure rates were $1.9 \%$. In our study, auxiliary procedures needed in $13.3 \%$. Three patients underwent SWL and one patient underwent ureteroscopy for steinstrasse.

Mean maximum stone diameter in our seris was $21.68 \pm 5.55 \mathrm{~mm}$ (range: $10-30$ $\mathrm{mm}$ ) which was comparable to the studies done by Yan et al.,(2012) and Bodakci et al., (2014) and Karatag et al. (2015) who reported mean stone diameter of, 18.5, $22.3 \mathrm{~mm}$ and $14.8 \mathrm{~mm}$ respectively.

Our mean operative time was (106.93 $\pm 13.89)$ with a range (85 - $135 \mathrm{~min}$.), which was similar to studies done by Yan et al., (2012), Bodakci et al., (2014) and Rashid et al., (2019) reported mean operative time 86.5 minutes with range (51-125 min), 85 minutes with range (25$135 \mathrm{~min}$ ) and 91 minutes with range (55 $130 \mathrm{~min}$ ) respectively. In our study mean hemoglobin loss was $1.1 \mathrm{~g} / \mathrm{dl}$ which was managed conservatively with no need for blood transfusion. Our result was comparable to studies done by Yan et al.
(2012), Bodakci et al., (2014) and Rashid et al. (2019) who reported mean hemoglobin loss $1.28,0.89 \mathrm{~g} / \mathrm{dl}$ and 1.08 $\mathrm{g} / \mathrm{dl}$ respectively. Mean hospital stay was $3.76 \pm 0.93$ days (range: $3-6$ days). Other studies done by Resorlu et al. (2012) and D'Souza et al. (2016) reported that mean hospital stay was 3.1 days and 3 days respectively.

Complication rate in our study was $23.3 \%$ which was comparable to other series done by Resorlu et al. (2012), Kumar et al. (2015), D'Souza et al. (2016) and Elsheemy et al. (2016) who reported complication rates $17 \%, 20.7 \%, 15 \%$ and $16.7 \%$ respectively. In our study; five patients $(16.7 \%)$ developed postoperative fever which required antibiotic and antipyretic. One patient $(3.3 \%)$ with renal pelvic perforation that was observed intraoperatively and managed by leaving nephrosyomy tube for five days. One patient $(3.3 \%)$ developed persistent leakage after removal of nephrostomy tube that was treated conservatively. In our series, renal isotope showed that renal function did not change postoperatively which was similar to studies done by Zeng et al. (2012) and Cicekbilek et al. (2015) who reported that renal function was preserved or even improved after percutaneous stone removal.

\section{CONCLUSION}

PNL is a safe and effective procedure for management of renal stones in children, with accepted stone clearance rates and postoperative morbidity in addition to relatively short hospital stay.

\section{REFERENCES}

1. Bilen CY, Gunay M, Ozden E, Inci K., Sarikaya $S$ and Tekgul S. (2010): Tubeless mini percutaneous nephrolithotomy in infants 
and preschool children: a preliminary report. J Urol., 184:2498-2503.

2. Bodakci M. Nuri, Daggulli M., Sancaktutar A. Ali, Soylemez H., Hatipoglu N. Kemal, Utangac M. Mazhar, Penbegul N., Ziypak T. and Bozkurt Y. (2014): Minipercutaneous nephrolithotomy in infants: a singlecenter experience in an endemic region in Turkey. Urolithiasis, 42:427-433.

3. Cicekbilek I. ,Resorlu b. ,Oguz U., Kara C. and Unsal A. (2015): Effect of percutaneous nephrolithotomy on renal functions in children: assessment by quantitative SPECT of 99mTc-DMSA, uptake by the kidneys, Renal Failure, 37:7, 1118-1121.

4. D'Souza $N$ and Paul $S$ (2016): Mini percutaneous nephrolithotomy for renal calculi in pediatric patients: A review of twenty cases. Urol Ann., 8:16-9.

5. El-Sheemy MS, Daw K, Habib E, Aboulela W, Fathy H, Shouman AM, El Ghoneimy M, Shoukry AI, Morsi HA and Badawy H (2016): Lower calyceal and renal pelvic stones in preschool children: A comparative study of mini-percutaneous nephrolithotomy versus extracorporeal shockwave lithotripsy, Division of Pediatric Urology, Aboul-Riche Children's Hospital,Cairo University, Cairo, Egypt, Int J Urol., 23(7):564-70.

6. Karatag T, Tepeler A, Silay MS, Bodakci MN, Buldu I, Daggulli M, Hatipoglu NK, Istanbulluoglu MO and Armagan A (2015): A Comparison of 2 Percutaneous Nephrolithotomy Techniques for the Treatment of Pediatric Kidney Stones of Sizes 10-20 mm: Microperc vs Miniperc, Urology, 85(5):1015-8.

7. Kumar A, Kumar N, Vasudeva P, Kumar R, Jha SK and Singh H (2015): A single center experience comparing miniperc and Shock wave lithotripsy (SWL) for treatment ofradioopaque 1-2 $\mathrm{cm}$ lower calyceal renal calculi in children: a prospective randomized study. J. Endourol., 29: 805-9.

8. Kumar R, Anand A, Saxena V, Seth A, Dogra P. Nath, Gupta P. Narmada (2011): Safety and efficacy ofPCNL for management of staghorn calculi in pediatric patients. J Pediatr Urol 7:248-251.

9. Muslumanoglu AY, Binbay M, Yuruk E, Akman T., Tepeler A., Esen T. and Tefekli A. H. (2011): Updated epidemiologic study of urolithiasis in Turkey. I: changing characteristics of urolithiasis. Urol Res., 39:309-314.

10. Rashid A. Omer, Shakhawan H. Amin, Mohammed A. Al Kadum, Sarbaz K. Mohammed and Noor B. (2019): MiniPercutaneous Nephrolithotomy for Complex Staghorn Stones in Children. Urol Int., 102:356-359.

11. Resorlu B, Unsal A, Tepeler A, Atis G, Tokatli Z, Oztuna D, Armagan A, Gurbuz C, Caskurlu $T$ and Saglam $R$ (2012): Comparison of retrograde intrarenal surgery and mini-percutaneous nephrolithotomy in children with moderate-size kidney stones: results of multi-institutional analysis. Urology, 80: 519-523.

12. Tekgül S, Dogan HS, Erdem E P. Hoebeke, R. Ko cvara, J.M. Nijman, C. Radmayr, M.S. Silay, Stein R. and Undre S. (2015): Guideline on Pediatric Urology, 1-130.

13. Unsal A, Resorlu B, Kara C, Bozkurt OF and Ozyuvali E. (2010): Safety and efficacy of percutaneous nephrolithotomy in infants, preschool age, and older children with different sizes of instruments. Urology 76:247-252.

14. Yan X. , Al-Hayek S. , Gan W. , Zhu W. , Li X. and Guo H. (2012): Minimally invasive percutaneous nephrolithotomy in preschool age children with kidney calculi (including stones induced by melaminecontaminated milk powder). Pediatr Surg Int; 28:1021-1024.

15. Zeng $G$, Zhao $Z$, Wan $S$, Zhong $W$ and $W u$ W (2013): Comparison of children versus adults undergoing mini- percutaneous nephrolithotomy: Large-scale analysis of a single institution. PLoS One, 8/66850. 
EVALUATION OF SAFETY AND EFFICACY OF PERCUTANEOUS...

\section{تقييم مدى أمان وفاعلية إستخدام منظار الكلى فى علاج علاج

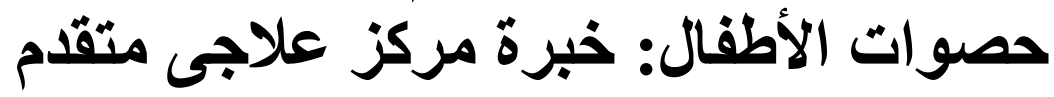

أحمد عبدالعظيم عبد العزيز متولى، ياسر على أحمد، السيد محمد موسى

قسم جراحة المسالك البولية، كلية الطب، جامعة الأزهر (القاهرة)

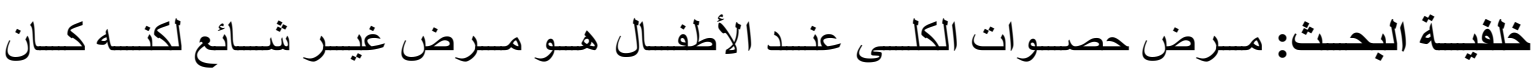

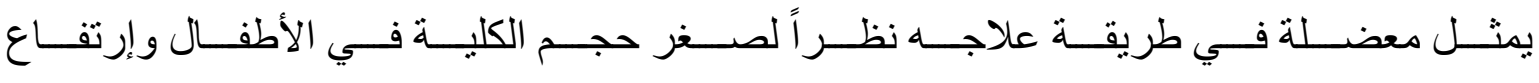

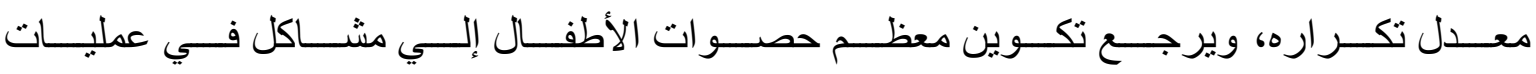
الأيض أو إلي عدوي الجهاز البولي.

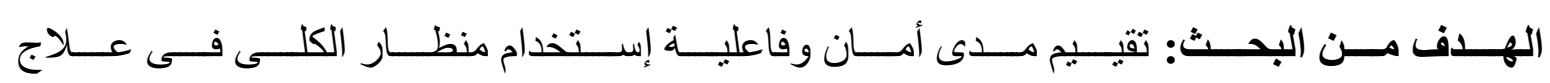

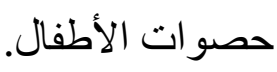

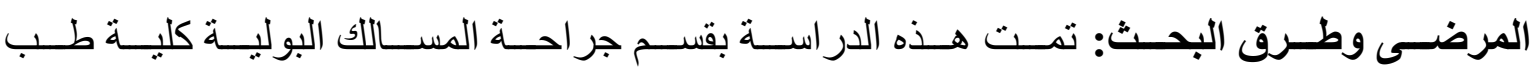

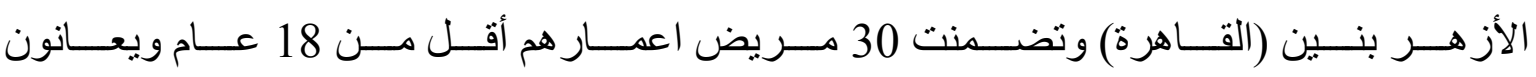

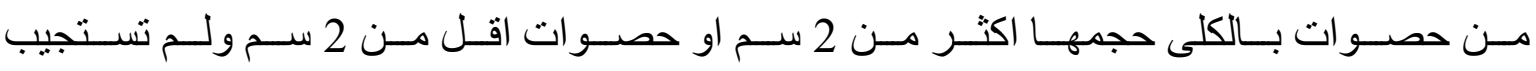

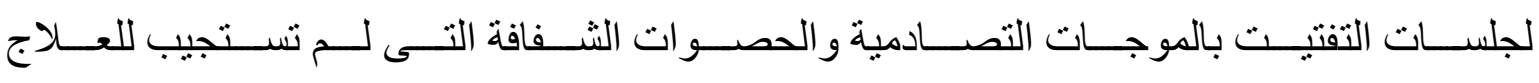

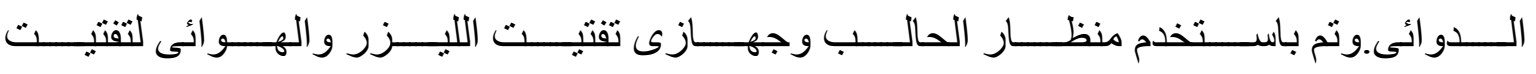

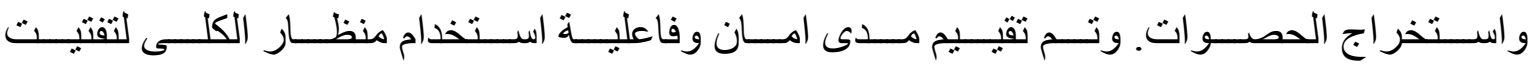

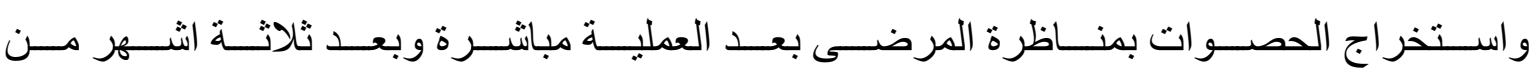
العملية.

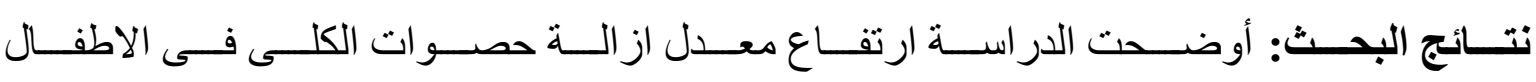
باستخدام المنظار مع حدوث مضاعفات بسيطة.

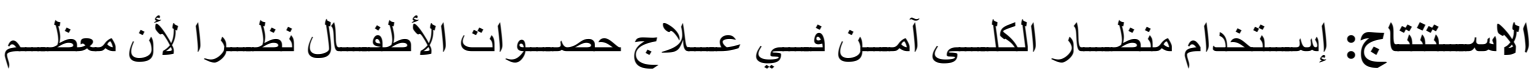
المضاعفات المصاحبة له بسيطة ويمكن التعامل معها بالعلاج التحفظي. 